\title{
Markers of atherosclerotic risk in patients with non-alcoholic fatty liver disease: A preliminary study
}

\author{
Roopa Rani Bhandary ${ }^{1, *}$, Sukanya Shetty ${ }^{2}$, Ashalatha Rao ${ }^{3}$, Srikrishna $\mathbf{U}^{4}$ \\ ${ }^{1}$ Assistant Professor, ${ }^{2}$ Professor and HOD, ${ }^{3}$ Professor, Department of Biochemistry, ${ }^{4}$ Professor and Head, Department of \\ Radiology, K. S. Hegde Medical Academy, Mangalore, Karnataka, India
}

*Correspondence Author:

Email: bhandarybio@yahoo.com

Received: $06^{\text {th }}$ December, 2017

Accepted: $09^{\text {th }}$ March, 2018

\begin{abstract}
Introduction: The prevalence of Non-Alcoholic Fatty Liver Disease (NAFLD) is rising continuously. Cardiovascular disease is one among the leading causes of morbidity and premature mortality in patients with NAFLD.

Aims and Objectives: To determine the risk of atherosclerosis in NAFLD subjects diagnosed by USG at K.S.Hegde Charitable hospital.

Materials and Methods: A cross-sectional study involving 203 persons diagnosed with NAFLD were included in the study. Subjects with alcoholic liver disease, renal failure, tuberculosis, hepatitis B and/or C and those on lipid lowering drug were excluded from the study. Lipid profile was measured and Atherogenic Index of Plasma (AIP) was calculated as log (TG/HDL-c). Categorization of the subjects with respect to risk of atherosclerosis was done based on serum LDL-c, non HDL-c and AIP. Statistical analysis was done using Chi Square test and $\mathrm{p}$ value $<0.05$ was considered significant.

Results: More than normal values were observed for serum total cholesterol, LDL-c, triglyceride and non HDL-c in high percentage of NAFLD subjects $(76.8 \%, 84.7 \%, 70.4 \%$ and $72.4 \%$ respectively). Serum HDL-c level was low in $53.2 \%$ subjects. $51.2 \%$ of subjects had high AIP and $23.6 \%$ had moderately high AIP.

Conclusion: Results of categorization of the subjects with respect to risk of atherosclerosis based on serum LDL-c, non HDL-c and AIP showed that high percentages of subjects were in moderate and high risk categories. AIP is probably a better marker to determine the risk of atherosclerosis.
\end{abstract}

Keywords: Atherogenic index of plasma, NAFLD, Non-alcoholic fatty liver disease, Lipids, Cardiovascular.

\section{Introduction}

Lipid, mainly as triglycerides, can accumulate in the liver for a variety of reasons. It is normal for the liver to contain some fat. However, if more than $5 \%-10 \%$ of the liver's weight is fat, then it is called a fatty liver (steatosis). Extensive accumulation is regarded as a pathologic condition. Fatty liver is also known as fatty liver disease.

Imbalance between production of triglycerides and its mobilisation as lipoprotein from the liver leads to fatty liver. It is a result of either over production of triglycerides (TG) or decreased synthesis of lipoproteins primarily very low density lipoproteins (VLDL). One of the major causes for the development of fatty liver is alcohol consumption. Therefore fatty liver disease has been classified into Alcoholic Fatty Liver Disease (AFLD) and non-alcoholic fatty liver disease (NAFLD). NAFLD represents a spectrum of conditions that span from asymptomatic steatosis to potentially deadly nonalcoholic steatohepatitis (NASH) Simple steatosis is generally a benign condition but NASH can progress to cirrhosis and liver failure. As prevalence of NAFLD seems to be increasing day by day, it has become a matter of global concern. ${ }^{1}$

NAFLD is widely considered to be the hepatic manifestation of metabolic syndrome. ${ }^{2-6}$ However it is also a risk factor for cardiovascular diseases. A study made by Chiang et al $2010^{(7)}$ demonstrated that nonobese and relatively healthy subjects with NAFLD have an increased risk of developing cardiovascular events. The severity of NAFLD correlates with increasing cardiovascular risks as well as underlying inflammatory status. The study also demonstrated that the risk predictive value of NAFLD is most significant in aged subjects and in subjects with increased level of high sensitivity C-reactive protein. This suggests its novel value in identifying subjects at high risk of developing cardiovascular disease. Parameters of dyslipidemia have been used in a number of ways to assess the cardiovascular risk such as serum LDL-c, non HDL-c and AIP.

In a study conducted in Hyderabad, India, on patients with T2DM and metabolic syndrome, the patients who also had NAFLD were found to have a higher AIP $(0.24 \pm 0.03)$ compared to that $(0.18 \pm 0.04)$ in patients without NAFLD although the difference was not statistically significant. ${ }^{8}$

This study aims to study the correlation of NAFLD with lipid profile and assess the risk of ischemic cardiovascular disease based on LDL-C, Non HDL-C and AIP 


\section{Materials and Methods}

All individuals attending the radiology department of K. S. Hegde Charitable Hospital for an abdominal scan during the period December 2010 to December 2013 were screened for liver steatosis. Among them, 203 persons diagnosed with NAFLD were included in the present study. A liver biopsy was not performed and a further distinction between NASH and simple steatosis was not made due to ethical issues. Informed consent was obtained from the study subjects.

The study design was approved by the ethical committee of K S Hegde Medical Academy (Nitte University). Subjects with alcoholic liver disease, chronic illnesses like renal failure, tuberculosis, with chronic hepatitis B and/or C, those on lipid lowering drugs and subjects not willing to participate in the study were excluded.

Relevant clinical details, anthropometric measurements and blood pressure were noted. Fatty liver was diagnosed, on ultrasonography, as diffuse increase in parenchymal echogenicity with progressive loss of clarity of portal vein and increased attenuation by the liver. $^{9}$

$5 \mathrm{ml}$ of venous blood was collected under aseptic condition from every subject after an overnight fast in red colour vacutainer and serum was separated for biochemical analysis.

Biochemical estimation of lipid profile was carried out in Clinical Biochemistry Laboratory at K S Hegde Medical College Hospital, in Cobas c311 Auto analyser from Roche Hitachi, using kits from the same company. Serum total cholesterol was estimated by cholesterol oxidase and peroxidase (CHOD-POD) method, serum triglycerides by Trinder method and serum HDLCholesterol by phosphotungstic acid method.

Serum LDL- Cholesterol was calculated by Friedewald Formula. ${ }^{10}$

Serum LDL cholesterol $=$ Serum Total cholesterol [Serum HDL-cholesterol + Serum Triglycerides/5]

The levels of serum LDL cholesterol were categorised based on the potential risk of atherosclerosis as shown in Table 1.

Table 1: Risk of atherosclerosis based on serum LDL-c level

\begin{tabular}{|l|c|}
\hline Serum LDL-c (mg/dL) & Risk of atherosclerosis \\
\hline$<100$ & Low \\
\hline $100-130$ & Medium \\
\hline$>130$ & High \\
\hline
\end{tabular}

NON-HDL CHOLESTEROL

Non-HDL cholesterol was calculated by using the formula ${ }^{11}$ :

Non-HDL Cholesterol $=$ Total cholesterol - HDL cholesterol

The levels of serum non HDL cholesterol were categorised based on the potential risk of atherosclerosis shown in Table 2.

Table 2: Risk of atherosclerosis based on serum NON- HDL-c level

\begin{tabular}{|l|c|}
\hline Non-HDL-c (mg/dL) & Risk of atherosclerosis \\
\hline$<130$ & Low \\
\hline $130-160$ & Medium \\
\hline$>160$ & High \\
\hline
\end{tabular}

ATHEROGENIC INDEX OF PLASMA (AIP) was calculated using the formula ${ }^{12}$ AIP $=$ Log [serum triglycerides $(\mathrm{mmol} / \mathrm{dL}) /$ serum HDL-c $(\mathrm{mmol} / \mathrm{dL})]$

The values for AIP were categorised based on the potential risk of atherosclerosis shown in Table 3.

Table 3: Risk of atherosclerosis based on AIP level

\begin{tabular}{|c|c|}
\hline AIP & Potential risk of atherosclerosis \\
\hline$<0.1$ & Low \\
\hline $0.1-0.24$ & Medium \\
\hline$>0.24$ & High \\
\hline
\end{tabular}

\section{Statistical Analysis}

a. Data analyses were performed using statistical package for social science (SPSS) version 13.

b. Data was analysed by both descriptive and inferential statistical methods.

c. Descriptive methods such as percentage, mean and standard deviation (SD) were used.

d. Inferential method used was Chi square test.

e. p value $<0.05$ was considered to be statistically significant. 


\section{Result}

In the present study, $61.1 \%(\mathrm{n}=124)$ of the subjects were females and $38.9 \%(\mathrm{n}=79)$ males. The mean age of the study participants were $47.3 \pm 11.11$ years.

The mean levels of all serum lipids in NAFLD subjects (cholesterol $=229.2 \pm 45.46 \mathrm{mg} / \mathrm{dL}$, triglycerides $=$ $181.8 \pm 70.37 \mathrm{mg} / \mathrm{dL}$ and $\mathrm{LDL}-\mathrm{c}=148.0 \pm 46.46 \mathrm{mg} / \mathrm{dL}$ ) were higher than the normal upper reference levels except for serum HDL-c (Table 4).

Table 4: Serum lipid profile in NAFLD subjects

\begin{tabular}{|l|c|c|c|}
\hline \multirow{2}{*}{$\begin{array}{c}\text { Serum lipid } \\
\text { profile }\end{array}$} & \multicolumn{3}{|c|}{$\begin{array}{c}\text { Serum lipid levels (mg/dL) } \\
\text { Mean } \pm \text { SD (Range) }\end{array}$} \\
\cline { 2 - 4 } & Females (124) & Males (79) & Total (203) \\
\hline $\begin{array}{l}\text { Total } \\
\text { cholesterol }\end{array}$ & $227.2 \pm 47.18$ & $232.5 \pm 45.4$ & $229.2 \pm 46.46$ \\
$(124.0-379.0)$ & $(107.0-344.0)$ & $(107.0-379.0)$ \\
\hline \multirow{2}{*}{ LDL-c } & $147.1 \pm 48.73$ & $149.5 \pm 42.89$ & $148.0 \pm 46.45$ \\
& $(54.0-296.0)$ & $(37.0-274.0)$ & $(37.0-296.0)$ \\
\hline \multirow{2}{*}{ Non HDL-c } & $182.7 \pm 47.2$ & $188.4 \pm 43.1$ & $184.9 \pm 45.61$ \\
& $(83.0-327.0)$ & $(85.0-304.0)$ & $(83.0-327.0)$ \\
\hline \multirow{2}{*}{ Triglycerides } & $169.9 \pm 66.40$ & $200.5 \pm 72.76$ & $181.8 \pm 70.37$ \\
& $(42.0-317.0)$ & $(75.0-509.0)$ & $(42.0-509.0)$ \\
\hline
\end{tabular}

Mean serum HDL-c level $(44.5 \pm 11.04 \mathrm{mg} / \mathrm{dL})$ in females was lower than the normal whereas it was within the normal reference range in males.(Table 5).

Table 5: Serum HDL-c levels in NAFLD subjects

\begin{tabular}{|c|c|}
\hline Subjects (no.) & $\begin{array}{c}\text { Serum HDL-c levels (mg/dL) } \\
\text { Mean } \pm \text { SD (Range) }\end{array}$ \\
\hline \multirow{2}{*}{ Females (124) } & $44.5 \pm 11.04$ \\
& $(22.0-77.0)$ \\
\hline \multirow{2}{*}{ Males (79) } & $44.1 \pm 11.53$ \\
$(22.0-60.0)$ \\
\hline
\end{tabular}

Significantly high numbers of NAFLD subjects were found to have high levels of serum total cholesterol, TG, LDL-c and non HDL-c $(\mathrm{p}<0.0001)$. The prevalence of more than normal serum total cholesterol was observed in $76.8 \%(\mathrm{n}=156)$ of subjects. However low serum cholesterol levels $(<130 \mathrm{mg} / \mathrm{dL})$ were found in $2.5 \%(\mathrm{n}=5)$ of subjects. Serum LDL-c was elevated in $84.7 \%(\mathrm{n}=172)$ of the subjects. Serum HDL-c level was low in $53.2 \%(\mathrm{n}=108)$ subjects. Serum TG level was found to be elevated in $70.4 \%(n=143)$ of the subjects. Non HDL-c was high in $72.4 \%(\mathrm{n}=147)$ of the subjects (Fig. 1).

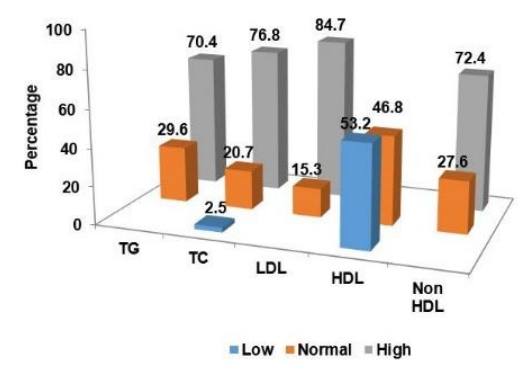

Fig. 1: Distribution of NAFLD subjects based on serum lipid profile
Among male subjects, high prevalence of increased serum TG $(82.3 \%, \mathrm{n}=65)$, total cholesterol $(79.7 \%$, $\mathrm{n}=63)$ and LDL-c $(87.3 \%, \mathrm{n}=69)$ was observed which was statistically significant $(\mathrm{p}<0.0001) .25 .3 \%$ of the male subjects had low HDL-c level and non HDL-c was high in $73.4 \%$ of the male subjects (Fig. 2).

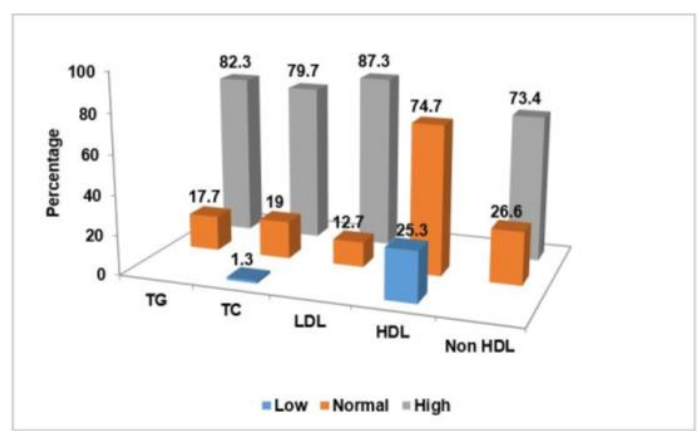

Fig. 2: Distribution of male NAFLD subjects based on serum lipid profile

Among female subjects also, the prevalence of increased serum total cholesterol $(75 \%, \mathrm{n}=93)$ and LDLc $(83.1 \% \mathrm{n}=103)$ were significantly high $(\mathrm{p}<0.0001)$, although the percentages with high serum cholesterol 
and LDL-c levels were slightly lower than those observed in males. The percentage of females having increased serum TG $(62.91 \% \quad n=78)$, was also significantly high $(\mathrm{p}<0.01)$. However it was significantly lower than that observed in males $(\mathrm{p}<0.01)$. Two of the female subjects had serum TG levels of $42 \mathrm{mg} / \mathrm{dL}$ which were slightly lower than the normal lower reference level (50 mg/dL). (Fig. 3)

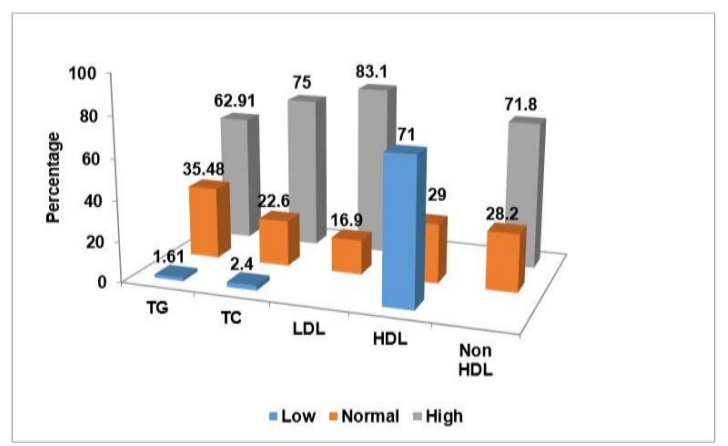

Fig. 3: Distribution of female NAFLD subjects based on serum lipid profile

Results of categorization of the subjects with respect to risk of atherosclerosis based on serum LDL-c, non HDL-c and AIP are shown in Fig. 4, 5 and 6.

Significantly high percentages of subjects were in moderate and high risk groups whichever parameter was used as the basis. $(\mathrm{p}<0.0001)$ Based on serum LDL-c and non HDL-c levels, the percentages of subjects in high risk $(68.0 \%$ and $70.9 \%$ respectively) and moderate risk categories (16.7\% and $18.8 \%$ respectively) were almost similar although the percentages were slightly higher when serum non HDL-c was considered. But these percentages $(51.2 \%$ and $23.6 \%)$ were much lower when AIP was considered (Fig. 4, 5).

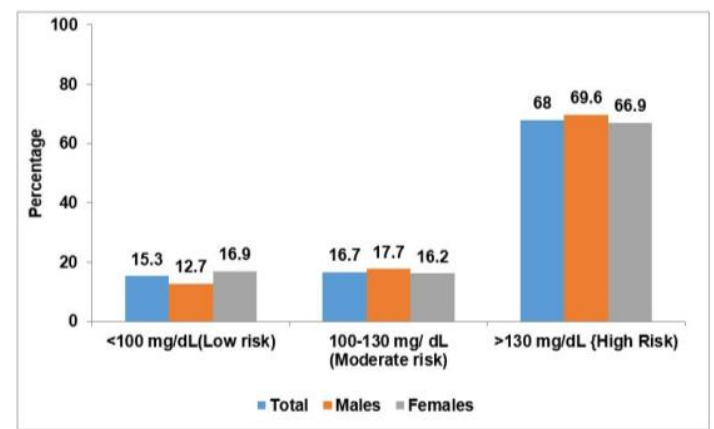

Fig. 4: Categorization of risk of atherosclerosis in NAFLD subjects based on their serum LDL-c level

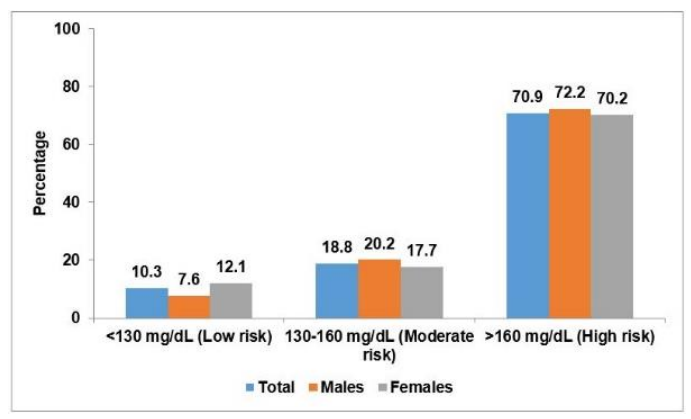

Fig. 5: Categorization of risk of atherosclerosis in NAFLD subjects based on their serum non HDL-c level

Significant difference $(\mathrm{p}<0.02)$ was found between the percentages of men and women indifferent risk categories based on AIP. Percentage of men in high risk category $(60.8 \%)$ was much higher than that of women $(45.2 \%)$ but no such significant difference was seen between the genders when serum LDL-c and non HDLc levels were used as the basis for risk categorization (Fig. 6).

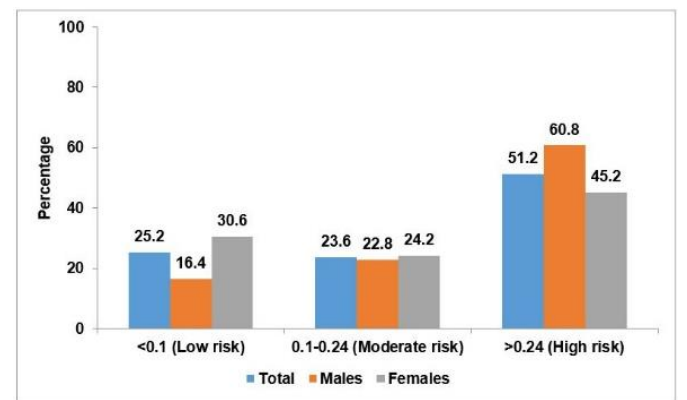

Fig. 6: Categorization of risk of atherosclerosis in NAFLD subjects based on their atherogenic index of plasma level

\section{Discussion}

Dyslipidemia is a well-established and important finding among NAFLD subjects. In almost every case of NAFLD subjects, in the present study, abnormality of either one or more of lipid profile parameters was observed. The most prevalent abnormality of lipid profile was increased serum LDL-c, $84.7 \%$ of the subjects had higher than $100 \mathrm{mg} / \mathrm{dL}$. This finding is supported by a study made by Hae-Kin Min et al (2012) wherein they observed an increased 2-hydroxy, 2-methyl glutaryl reductase (HMG CoA reductase) expression and decreased expression of LDL receptors and bile acid synthetic enzymes resulting in high serum LDL-c among NAFLD subjects. ${ }^{13}$ Studies on lipoprotein metabolism and NAFLD revealed that insulin resistance seen in NAFLD subjects increases VLDL synthesis and secretion by the liver in an attempt to maintain normal hepatic lipid content. This results in abnormal level of lipoprotein in the plasma (elevated plasma VLDL and 
LDL concentration). ${ }^{14-16}$ Different studies on NAFLD patients have shown elevated plasma LDL level. ${ }^{17,18}$

Several cross-sectional studies from the West have found that subjects with NAFLD have high TG levels. ${ }^{19-}$ ${ }^{21}$ In Indian population, the subjects with NAFLD had significantly higher values of total cholesterol and TG. ${ }^{22,23}$

The mean serum TG was $207.2 \pm 131.7 \mathrm{mg} / \mathrm{dL}$ among NAFLD subjects in a South Korean study. ${ }^{24}$ It was higher than normal in the present study, being 181.8 $\pm 70.37 \mathrm{mg} / \mathrm{dL}$.

In the study by Madan et al (2006) $)^{25}$ from All India Institute of Medical Sciences (AIIMS), $40.8 \%$ of the subjects had hypertriglyceridemia and $36.4 \%$ had low HDL-c. Percentages of NAFLD subjects with high triglyceridemia and low serum HDL-c were much higher in the study done in Latur $(67.14 \%$ and $62.9 \%$ respectively). ${ }^{26}$

In the present study, hypertriglyceridemia was observed in $70.4 \%$ of the subjects, the percentage being higher than those in other studies. But the percentage of subjects with low HDL-c (53.2\%) was lower than that reported in Latur study ${ }^{26}$ and higher than that observed by Madan et al $2006 .{ }^{25}$

Percentages of subjects with hypercholesterolemia and high serum LDL-c observed in the present study (76.8\% and $84.7 \%$ respectively) were also higher than those observed in the Latur study $(45.71 \%$ and $34.28 \%$ respectively). ${ }^{26}$

The high levels of serum LDL-c and low levels of serum HDL-c have shown to be strongly associated with increased risk of atherosclerosis and coronary artery disease in many studies. ${ }^{27-29}$

In recent times, the level of serum non HDL-c is considered by some to be superior to serum LDL-c in prediction of cardiovascular complications. ${ }^{30-32}$

In the present study, $70.9 \%$ of subjects had serum non HDL-c levels in the high risk category and $18.8 \%$ in the moderate risk category. These percentages were similar to those observed with respect to LDL-c (68\% and $16.7 \%$ respectively).

Based on many studies, it is now thought that the particle sizes of LDL and HDL also influence development of atherosclerosis and just not their cholesterol content. It has been shown that small particle sizes of LDL and HDL are atherogenic. ${ }^{33}$ It also has been shown that the esterification rate of free cholesterol in HDL expressed as FER ${ }_{\mathrm{HDL}}$, is inversely related to the size of HDL particles, and predicts particle size of HDL as well as that of LDL. ${ }^{12,34}$ According to Murakami et al 1995, TG are the major determinants of cholesterol esterification/ transfer and HDL remodelling in plasma. ${ }^{(35)}$ They are also implicated in increasing population of small, dense LDL. ${ }^{36}$ High serum TG and low HDL-c induce both an increase in the proportion of small HDL particles and, hence, the $\log$ of ratio of molar concentrations of serum TG and HDL-c has been used to predict the risk of atherosclerosis and is called as AIP. ${ }^{12}$
$51.2 \%$ of subjects in the present study had high AIP and $23.6 \%$ had moderately high AIP. These figures indicate lower chances of incidence of atherosclerosis than those predicted by the levels of serum LDL-c and HDL-c. As AIP calculation involves triglyceride level which is a major determinant of particle size of LDL and HDL, it is probably a better marker for risk of atherosclerosis.

\section{Conclusion}

Risk of atherosclerosis based on serum LDL-c, non HDL-c and AIP showed significantly high percentages of NAFLD subjects in high and moderate risk groups. AIP is probably a superior marker as it reflects alteration in both TG and HDL-c levels.

\section{References}

1. Bellentani S, Scaglioni F, Marino M, Bedogni G. Epidemiology of non-alcoholic fatty liver disease. Digestive diseases. 2010;28(1):155-61.

2. Cortez-Pinto H, Camilo ME, Baptista A, De Oliveira AG, De Moura MC. Non-alcoholic fatty liver: another feature of the metabolicsyndrome?. Clinical Nutrition. 1999 Dec 31;18(6):353-8.

3. Marceau P, Biron S, Hould FS, Marceau S, Simard S, Thung SN, Kral JG. Liver pathology and the metabolic syndrome $\mathrm{X}$ in severe obesity. The Journal of Clinical Endocrinology \& Metabolism. 1999 May 1;84(5):1513-7.

4. Pagano G, Pacini G, Musso G, Gambino R, Mecca F, Depetris N, Cassader M, David E, Cavallo-Perin P, Rizzetto M. Nonalcoholic steatohepatitis, insulin resistance, and metabolic syndrome: further evidence for an etiologic association. Hepatology. $2002 \mathrm{Feb}$ 1;35(2):367-72.

5. Marchesini G, Forlani G. NASH: from liver diseases to metabolic disorders and back to clinical hepatology. Hepatology. 2002 Feb 1;35(2):497-9.

6. Angelico F, Del Ben M, Conti R, Francioso S, Feole K, Maccioni D, ANTONINI T, Alessandri C. Non-alcoholic fatty liver syndrome: A hepatic consequence of common metabolic diseases. Journal of gastroenterology and hepatology. 2003 May 1;18(5):588-94.

7. Chiang C, Huang C, Chan W, Chen J, Leu H. The severity of non-alcoholic fatty liver disease correlates with high sensitivity $\mathrm{C}$-reactive protein value and is independently associated with increased cardiovascular risk in healthy population. Clinical Biochemistry. 2010; ( 18):1399-404

8. Alim M, Sahay RK, Hafiz N, Prabhakar B, Ibrahim M. Cardiovascular disease risk assessment in diabetes and metabolic syndrome patients with and without nonalcoholic fatty liver disease. International Journal of Clinical Trials. 2015 Nov 22;2(4):91-6.

9. Mishra P, Younossi ZM. Abdominal ultrasound for diagnosis of nonalcoholic fatty liver disease (NAFLD). Am J Gastroenterol 2007;102(12):2716-7.

10. Friedewald WT, Levy RI, Fredrickson DS. Estimation of the concentration of low-density lipoprotein cholesterol in plasma, without use of the preparative ultracentrifuge. Clinical chemistry. 1972 Jun 1;18(6):499-502.

11. Virani SS. Non-HDL cholesterol as a metric of good quality of care. Tex Heart Inst J. 2011;38:160-2.

12. Dobiášová $\mathrm{M}$, Frohlich J. The plasma parameter log (TG/HDL-C) as an atherogenic index: correlation with 
lipoprotein particle size and esterification rate inapoblipoprotein-depleted plasma (FER HDL). Clinical biochemistry. 2001 Oct 31;34(7):583-8.

13. Min HK, Kapoor A, Fuchs M, Mirshahi F, Zhou H, Maher J, Kellum J, Warnick R, Contos MJ, Sanyal AJ. Increased hepatic synthesis and dysregulation of cholesterol metabolism is associated with the severity of nonalcoholic fatty liver disease. Cell metabolism. 2012 May 2;15(5):665-74.

14. Adiels M, Olofsson SO, Taskinen MR, Borén J. Overproduction of very low-density lipoproteins is the hallmark of the dyslipidemia in the metabolic syndrome. Arteriosclerosis, thrombosis, and vascular biology. 2008 Jul 1;28(7):1225-36.

15. Haidari M, Leung N, Mahbub F, Uffelman KD, KohenAvramoglu R, Lewis GF, et al. Fasting and Postprandial Overproduction of Intestinally Derived Lipoproteins in an Animal Model of Insulin Resistance Evidence That Chronic Fructose Feeding In The Hamster Is Accompanied By Enhanced Intestinal De Novo Lipogenesis And Apob48-Containing Lipoprotein Overproduction. Journal of Biological Chemistry. 2002 Aug 30;277(35):31646-55.

16. Zoltowska M, Ziv E, Delvin E, Stan S, Bar-On H, Kalman R, Levy E. Circulating lipoproteins and hepatic sterol metabolism in Psammomys obesus prone to obesity, hyperglycemia and hyperinsulinemia. Atherosclerosis. $2001 \mathrm{Jul}$ 31;157(1):85-96.

17. Barshop NJ, Sirlin CB, Schwimmer JB, Lavine JE. Review article: epidemiology, pathogenesis and potential treatments of paediatric non-alcoholic fatty liver disease. Alimentary pharmacology \& therapeutics. $2008 \mathrm{Jul}$ 1;28(1):13-24.

18. Singh DK, Sakhuja P, Malhotra V, Gondal R, Sarin SK. Independent predictors of steatohepatitis and fibrosis in Asian Indian patients with non-alcoholic steatohepatitis. Digestive diseases and sciences. 2008 Jul 1;53(7):196776.

19. Church TS, Kuk JL, Ross R, Priest EL, Biltoff E, Blair $\mathrm{SN}$. Association of cardiorespiratory fitness, body mass index, and waist circumference to nonalcoholic fatty liver disease. Gastroenterology. 2006 Jun 30;130(7):2023-30.

20. Clark JM. The epidemiology of nonalcoholic fatty liver disease in adults. J Clin Gastroenterol. 2006; 40:5-10.

21. Leite NC, Salles GF, Araujo AL, Villela-Nogueira CA, Cardoso CR. Prevalence and associated factors of nonalcoholic fatty liver disease in patients with type-2 diabetes mellitus. Liver International. 2009 Jan 1;29(1):113-9.

22. Sathiaraj E, Chutke M, Reddy MY, Pratap N, Rao PN, Reddy DN, et al. A case-control study on nutritional risk factors in non-alcoholic fatty liver disease in Indian population. European journal of clinical nutrition. 2011 Apr 1;65(4):533-7.

23. Bajaj S, Nigam P, Luthra A, Pandey RM, Kondal D, Bhatt SP, Wasir JS, Misra A. A case-control study on insulin resistance, metabolic co-variates \& prediction score in non-alcoholic fatty liver disease.

24. Kim HJ, Lee KE, Kim DJ, Kim SK, Ahn CW, Lim SK, et al. Metabolic significance of nonalcoholic fatty liver disease in nonobese, nondiabetic adults. Arch Intern Med. 2004 Oct 25;164(19):2169-75.

25. Madan K, Batra Y, Gupta SD, Chander B, Rajan KDA, Tewatia MS, et al. Non-alcoholic fatty liver disease may not be a severe disease at presentation among Asian Indians. World J Gastroenterol. 2006 June 7;12(21):3400-5.
26. Mahaling DU, Basavaraj MM, Bika AJ. Comparison of lipid profile in different grades of non-alcoholic fatty liver disease diagnosed on ultrasound. Asian Pacific journal of tropical biomedicine. 2013 Nov 30;3(11):90712.

27. Cummings KC. Lipid and cardiac risk profiles. Clinical Chemistry. 2003;47:407-9.

28. Castelli WP. Cholesterol and lipids in the risk of coronary artery disease--the Framingham Heart Study. The Canadian journal of cardiology. 1988 Jul;4:5A-10A.

29. Igweh JC, Nwagha IU, Okaro JM. The effects of menopause on the serum lipid profile of normal females of South East Nigeria. Nigerian journal of physiological sciences. 2006 Jul 13;20(1):48-53.

30. Sniderman AD, Williams K, Contois JH, Monroe HM, McQueen MJ, de Graaf J, et al. A meta-analysis of lowdensity lipoprotein cholesterol, non-high-density lipoprotein cholesterol, and apolipoprotein B as markers of cardiovascular risk. Circulation: Cardiovascular Quality and Outcomes. 2011 May 1;4(3):337-45.

31. DeFilippis AP, Blaha MJ, Martin SS, Reed RM, Jones SR, Nasir K, et al. Nonalcoholic fatty liver disease and serum lipoproteins: the Multi-Ethnic Study of Atherosclerosis. Atherosclerosis. $2013 \mathrm{Apr}$ 30;227(2):429-36.

32. Emerging Risk Factors Collaboration, Di Angelantonio E, Sarwar N, Perry P, Kaptoge S, Ray KK, et al. Major lipids, apolipoproteins, and risk of vascular disease. JAMA. 2009 Nov 11;302(18):1993-2000.

33. Drexel H, Amann FW, Rentsch K, Neuenschwander C, Luethy A, Khan SI, et al. Relation of the level of highdensity lipoprotein subfractions to the presence and extent of coronary artery disease. The American journal of cardiology. 1992 Aug 15;70(4):436-40.

34. Dobiasova M, Stribrna J, Pritchard PH, Frohlich JJ. Cholesterol esterification rate in plasma depleted of very low and low density lipoproteins is controlled by the proportion of HDL2 and HDL3 subclasses: study in hypertensive and normal middle-aged and septuagenarian men. Journal of lipid research. 1992 Oct 1;33(10):1411-8.

35. Murakami T, Michelagnoli S, Longhi R, Gianfranceschi G, Pazzucconi F, Calabresi L, et al. Triglycerides are major determinants of cholesterol esterification/transfer and HDL remodeling in human plasma. Arteriosclerosis, thrombosis, and vascular biology. $1995 \mathrm{Nov}$ 1;15(11):1819-28.

36. Guérin M, Le Goff W, Lassel TS, Van Tol A, Steiner G, Chapman MJ. Proatherogenic Role of Elevated CE Transfer From HDL to VLDL1 and Dense LDL in Type 2 Diabetes Impact of the Degree of Triglyceridemia. Arteriosclerosis, thrombosis, and vascular biology. 2001 Feb 1;21(2):2828. 